\title{
EFECTO DE DOS MÉTODOS DE CONGELACIÓN SOBRE LA VIABILIDAD ESPERMÁTICA DE SEMEN DE VERRACO
}

\author{
Effect of Two Freezing Methods on Sperm Viability of BoAr Semen
}

Mateo Carpio C. ${ }^{1}$, José Cadillo C. ${ }^{1}$ y Edwin Mellisho S. ${ }^{1,2}$

\section{Resumen}

\begin{abstract}
El objetivo del presente trabajo fue evaluar el efecto de dos métodos de congelación sobre la viabilidad espermática de semen de verraco. Se utilizaron seis eyaculados (dos por macho), de tres verracos adultos de las razas Hampshire, Duroc y Landrace. Se evaluó el volumen, motilidad y concentración espermática de cada eyaculado. Posteriormente, el semen fue diluido con solución BTS (Beltsville Thawing Solution) y centrifugado a $1500 \mathrm{rpm}$ por $10 \mathrm{~min}$ para retirar el plasma. El pellet (porción espermática) obtenido fue extendido con dilutor de congelación (A y B), enfriado y equilibrado a $5{ }^{\circ} \mathrm{C}$ por 2 horas previas a la congelación. El semen equilibrado fue criopreservado usando dos métodos de congelamiento: a) en pellets colocando alícuotas de $0.25 \mathrm{ml}$ de semen equilibrado en agujeros preparados en la superficie del bloque de hielo seco manteniéndolo por 2 min y luego vertiéndolo al nitrógeno líquido; y b) en pajillas de $0.5 \mathrm{ml}$, exponiéndolas al vapor de nitrógeno líquido a $7 \mathrm{~cm}$ de altura por $10 \mathrm{~min}$ (dentro de una caja de tecnopor) para luego verterlas al nitrógeno liquido. No se encontró diferencias significativas entre la motilidad individual y proporción de espermatozoides vivos del semen congelado en pellets (40.1 y $48.8 \%)$ vs. pajillas (34.5 y $40.7 \%)$, respectivamente.
\end{abstract}

Palabras clave: verraco, semen, criopreservación, espermatozoide

\section{Abstract}

The objective of this experiment was to evaluate the effect of two freezing methods on the spermatic viability of boar semen. Six collects ( 2 ejaculates per male) of three adult boars (Hampshire, Duroc and Landrace) were used. Immediately after the collection, volume, motility and spermatic concentration of each ejaculate were evaluated. Then, the semen was diluted with BTS solution (Beltsville Thawing Solution) and centrifuged at $1500 \mathrm{rpm}$ for $10 \mathrm{~min}$ for plasma withdrawal. The pellet (spermatic portion) was diluted with freezing dilutor (A and B), cooled and equilibrated at $5{ }^{\circ} \mathrm{C}$ for two hours before freezing. The equilibrated semen was cryopreserved using two freezing methods: a) in pellets placing $0.25 \mathrm{ml}$ aliquota of semen in holes prepared on the surface of a dry ice block for 20 min and then, pouring them in liquid nitrogen; and b) in straws of $0.5 \mathrm{ml}$ exposing them at $7 \mathrm{~cm}$ over liquid nitrogen steam for $10 \mathrm{~min}$ (in a styrofoam box). The results showed no

\footnotetext{
${ }^{1}$ Departamento de Producción Animal, Facultad de Zootecnia, Universidad Nacional Agraria La Molina (UNALM), Lima

${ }^{2}$ E-mail: emellisho@lamolina.edu.pe
} 
statistically differences amongst individual motility and live spermatozoa percentage in semen frozed in pellets (40.1 and $48.8 \%$ ) as compared to straws (34.5 and $40.7 \%$ ).

Key words: boar, semen, cryopreservation, spermatozoa

\section{INTRODUCCIÓN}

La conservación a largo plazo del semen es económicamente importante y altamente deseable para mantener y conservar germoplasma, preservar la diversidad genética y mejorar la eficiencia reproductiva de los animales. La primera vez que se realizó con éxito la congelación de material seminal fue en 1949 cuando Polge et al. demostraron el poder crioprotector del glicerol.

Los primeros trabajos en congelación de semen en la especie porcina datan de hace más de 30 años (Pursel y Johnson, 1975; Westendorf et al., 1975). Se ha demostrado que los espermatozoides de verraco son más sensibles a los eventos asociados a la criopreservación, así como a los procesos de congelación y descongelación (Watson, 1995), que otras especies como bovinos y humanos; produciéndose daños en la membrana plasmática y organelos de la célula como resultado del estrés osmótico, shock de enfriamiento y formación de hielo intracelular (Johnson et al., 2000). La variabilidad en las tasas de viabilidad espermática post descongelación demuestra que aún existen factores no esclarecidos en esta especie, requiriéndose de estudios adicionales.

El semen congelado de verraco ha sido utilizado principalmente para la introducción y mejoramiento genético de núcleos de selección (Holt, 1997), y no tanto para el servicio de marranas en las unidades de producción comerciales. Ello se debe principalmente a que los resultados de fertilidad son más bajos que los obtenidos con semen fresco o la monta natural (Johnson et al., 2000). En el Perú, la diseminación de material genético de verracos de alto valor usando insemina- ción artificial es muy limitada debido a la falta de un método de conservación de semen que otorgue tasas de viabilidad espermática aceptables.

Ante esta problemática, el presente trabajo tuvo como objetivo evaluar el efecto de dos métodos de congelación sobre la viabilidad espermática de semen de verraco.

\section{Materiales y Métodos}

\section{Animales}

El trabajo se llevó a cabo en las instalaciones del Laboratorio de Biotecnología Reproductiva y la Granja de Cerdos de la Universidad Nacional Agraria La Molina, Lima. Se utilizaron eyaculados de tres verracos adultos ( 2 eyaculados por verraco colectados con intervalo de cuatro días) de las razas Hampshire, Duroc y Landrace Belga. Los animales fueron mantenidos en corrales individuales de piso de tierra.

\section{Colección de Semen}

Los verracos fueron trasladados de su corral individual al área de colección. A la monta del maniquí y protrusión del pene, el técnico sujetó el glande del pene con mano enguantada y presionó ligeramente, estimulando la eyaculación. El semen se recibió en un termo provisto de dos capas de gasa fina como filtro. La fracción espermática se recuperó en el termo y se trasladó al laboratorio donde se realizó la evaluación de semen inicial previo al proceso de dilución. Se cuantificó el volumen, la motilidad y la concentración espermática. 


\section{Preparación del Dilutor de Semen}

Se preparó la solución BTS (Beltsville Thawing Solution) como dilutor de congelación que contiene $37 \mathrm{~g} / \mathrm{l}$ de glucosa, $1.25 \mathrm{~g} / \mathrm{l}$ de EDTA, 6 g/l de citrato de sodio, $1.25 \mathrm{~g} / \mathrm{l}$ de bicarbonato de sodio y $0.75 \mathrm{~g} / \mathrm{l}$ de cloruro de potasio, diluidos en agua destilada estéril (Pursel y Jonson, 1975). A la solución base, se le adicionó 3\% de yema de huevo y se le centrifugó a $2000 \mathrm{rpm}$ por $10 \mathrm{~min}$ para eliminar los sólidos (grumos). La solución clarificada se separó en una primera fracción, denominada dilutor $\mathrm{A}$, y en una segunda fracción denominada dilutor $\mathrm{B}$, a la que se le adicionó $7 \%$ de glicerol.

\section{Procesamiento de Semen}

Se utilizó el método Beltsville (Pursel y Johnson, 1975) modificado para procesar el semen de verraco. El semen, a su llegada al laboratorio, era mezclado 1:1 con el dilutor BTS (sin yema, ni glicerol), equilibrando por 2 horas a $18-20{ }^{\circ} \mathrm{C}$, para luego remover la mezcla y se centrifugar a $1500 \mathrm{rpm}$ por 10 min. Se recuperó la porción espermática libre de plasma del fondo del tubo y se diluyó con el dilutor A (BTS). Se inició el descenso continuo de la temperatura $\left(1^{\circ} \mathrm{C} / \mathrm{min}\right)$ del semen diluido hasta 4 a $5^{\circ} \mathrm{C}$. Se completó la dilución con el dilutor B (BTS) para obtener una concentración final de 250 millones/ml. Después, se realizó el equilibrio de la mezcla a $5{ }^{\circ} \mathrm{C}$ durante 2 horas.

\section{Congelación de Semen}

El semen se congeló usando dos métodos de congelación: en pellets y en pajillas.

- Congelación de semen en pajillas

El semen equilibrado por 2 horas $\left(5^{\circ} \mathrm{C}\right)$ fue vaciado en pajillas de $0.5 \mathrm{ml}$ (Cassou - IMV, Francia) y sellado con alcohol polivinílico. Las pajillas se colocaron sobre una rejilla ubicada a $7 \mathrm{~cm}$ de la superficie del nitrógeno líquido, dentro de una caja de tecnopor de 25 x 20 x $15 \mathrm{~cm}$ (largo x an- cho $\mathrm{x}$ alto, respectivamente). Se tapó completamente y se lo mantuvo por 10 min para que el vapor del nitrógeno líquido enfriara y congelara las pajillas de semen. Luego, las pajillas se sumergieron en el nitrógeno líquido y se almacenaron en las canastillas del tanque criogénico.

\section{- Congelación de semen en pellets}

Se forjaron hoyuelos con capacidad de $0.25 \mathrm{ml}$ en la superficie del bloque de hielo seco $\left(\mathrm{CO}_{2}\right.$ sólido). Se colocó 0.25 $\mathrm{ml}$ de semen equilibrado $\left(5^{\circ} \mathrm{C}\right)$, en cada agujero, manteniéndolo por dos minutos, permitiendo que ocurra la congelación del semen. Los pellets resultantes se colocaron en las canastillas del tanque criogénico y se introdujeron en el nitrógeno líquido.

\section{Evaluación de Viabilidad Espermática}

La evaluación de la viabilidad espermática post descongelación se realizó al día siguiente del proceso, la cual se inició retirando el pellet del tanque criogénico y colocándolo dentro de un tubo de vidrio estéril y seco ubicado en una gradilla en baño de agua a $38^{\circ} \mathrm{C}$ por $60 \mathrm{~s}$, hasta que cambiase de estado sólido a líquido. Luego, se trasladó la muestra a baño maría a $35^{\circ} \mathrm{C}$, mientras se realizaba la evaluación.

La viabilidad espermática post-descongelación se evaluó por triplicado mediante los parámetros de motilidad individual progresiva y porcentaje de espermatozoides vivos. La motilidad se evaluó en microscopio a 100x colocando una muestra de semen descongelado encima del portaobjetos y cubierto con una lámina. Los resultados se cuantificaron en porcentaje de espermatozoides mótiles y con movimiento progresivo. El porcentaje de espermatozoides vivos se determinó con la técnica de tinción de eosina y nigrosina. La diferencia de color de la cabeza del espermatozoide indicó la presencia de espermatozoides muertos (teñidos de rosado) o vivos (transparentes). 


\section{Análisis Estadístico}

Los parámetros de motilidad individual progresiva y porcentaje de espermatozoides vivos, fueron analizados estadísticamente mediante la prueba de chi-cuadrado a un nivel de significancia de $?=0.05$ para determinar las diferencias entre los dos métodos de congelación.

\section{Resultados y Discusión}

La fracción espermática tuvo un volumen de $140 \pm 31 \mathrm{ml}$, la concentración espermática fue de $352 \pm 93$ millones $/ \mathrm{ml}$ y la motilidad individual progresiva de $80 \pm 2 \%$. Además, los resultados de motilidad individual evaluados durante el procesamiento del semen mostraron una reducción paulatina, pero no marcada, siendo las motilidades individuales de 80,77 y $74 \%$ en la evaluación inicial, después de centrifugar y previa a la congelación, respectivamente.

La motilidad individual progresiva y porcentaje de espermatozoides vivos de semen descongelado fue similar en los dos métodos de congelación (Cuadro 1).

Se han descritos diversos efectos negativos de la congelación sobre las características fisiológicas de los espermatozoides de verraco, tales como baja reducción en la motilidad, daño acrosomal y reducida capacidad fecundante (Watson y Plumer, 1985; Holt, 1997; Johnson et al., 2000; Peláez et al.,
2002). En la mayoría de los casos, la motilidad de los espermatozoides de verraco después de la congelación y descongelación es menor al $50 \%$ y su capacidad fecundante fluctúa entre el 35 al 40\% (Watson, 1996).

En el presente trabajo, el método de congelación en pajillas de $0.5 \mathrm{ml}(34.5 \%)$ o pellets $(40.1 \%)$ no afectó la motilidad individual espermática. Motilidades similares en pajillas fueron encontradas por Córdova-Izquierdo et al. (2004); sin embargo, Pursel y Johnson (1975) reportaron una motilidad superior para semen congelado en pellets (40 al 50\%) versus pajillas ( 20 al $40 \%$ ), sugiriendo que los métodos de congelación influyen en las respuestas de viabilidad espermática.

Las diferencias entre los valores de motilidad individual con el porcentaje de espermatozoides vivos podría deberse a que, en el primer caso, la evaluación tiene un carácter subjetivo por parte del evaluador. Salisbury et al. (1978) indica que la subjetividad del examen de motilidad espermática de semen descongelado hace que muchas veces la correlación con la fertilidad sea baja, a pesar de que se trata de un parámetro ampliamente utilizado en los centros de inseminación. Por otro lado, las pruebas de tinción (eosina-nigrosina) producen información concerniente a la integridad de membrana espermática de la cabeza, dando mayor información de la viabilidad espermática (Chan et al., 1991). Guthrie y Welch (2005) reportan estas mismas diferencias al congelar semen de verraco con dilutor BTS $25.8 \%$ de motilidad individual y $44.2 \%$ espermatozoides vivos.

Cuadro 1. Viabilidad espermática de semen porcino criopreservado en hielo seco (pellets) y nitrógeno líquido (pajillas)

\begin{tabular}{lccc}
\hline Métodos de congelación & $\mathrm{N}^{\mathrm{o}}$ & $\begin{array}{c}\text { Motilidad individual } \\
(\%)\end{array}$ & $\begin{array}{c}\text { Espermatozoides vivos } \\
(\%)\end{array}$ \\
\hline Pajilla de $0.5 \mathrm{ml}$ & 6 & $34.5 \pm 5.7^{\mathrm{a}}$ & $40.7 \pm 5.6^{\mathrm{a}}$ \\
Pellets de $0.25 \mathrm{ml}$ & 6 & $40.1 \pm 5.5^{\mathrm{a}}$ & $48.8 \pm 4.9^{\mathrm{a}}$ \\
\hline
\end{tabular}

${ }^{a, b}$ Letras diferentes dentro de columnas indican diferencia s significativas $(p<0.05)$ 


\section{Conclusiones}

Se obtuvo buenas tasas de viabilidad espermática en la criopreservación de semen de verraco mediante la congelación en pellets y en pajillas.

\section{Literatura Citada}

1. Chan PJ, Tredway DR, Corselli J, Pang S, Su BC. 1991. Combined supravital staining and hypoosmotic swelling. Hum Reprod 6: 1115-1118.

2. Córdova-Izquierdo A, Córdova-Jiménez M, Córdova-Jiménez C, Pérez-Gutiérrez J, Martín-Rillo S. 2005. Congelación de semen de verraco en dos tipos de pajillas y capacidad fecundante in vitro de los espermatozoides. Cienc Ergo Sum 12(3): 271-272.

3. Guthrie HD, Welch GR. 2005. Impact of storage prior to cryopreservation on plasma membrane function and fertility of boar sperm. Theriogenology 63: 396-410.

4. Holt WV. 1997. Alternative strategies for the long-term preservation of spermatozoa. Reprod Fert Develop 9: 309-319.

5. Jhonson LA, Weitze KF, Fiser P, Maxwell WMC. 2000. Storage of boar semen. Anim Reprod Sci 62: 143-172.
6. Peláez J, Domínguez JC, Peña FJ, Robles P, Ferraras A, Alegre B. 2002. Conceptos básicos en criobiología del espermatozoide. Porci. Aula Veterinaria. Monografía de Actualidad. Tratado de Ganado Porcino 72: 23-36.

7. Polge C, Smith AV, Parkes AS. 1949. Revival of spermatozoa after vitrification and dehydration at low temperatures. Nature 164: 666-668.

8. Pursel VG, Johnson LA. 1975. Freezing of boar spermatozoa: fertilizing capacity with concentrated semen and a new thawing procedure. J Anim Sci 40: 99-102.

9. Watson PF. 1995. Recent development and concepts in the cryopreservation of spermatozoa and the assessment of their post-thawing function. Reprod Fert Develop 7: 871-891.

10. Watson PF. 1996. Cooling of spermatozoa and fertilizing capacity. Reprod Dom Anim 31: 135-140.

11. Watson PF, Plumer JM. 1985. The responses of boar sperm membranes to cold shock and cooling. Proc First Internat Conference on Deep Freezing of Boar Semen. Uppsala, Sweden. p 113-127.

12. Westendorf P, Richter L, Treu H. 1975. Deep freezing of boar semen: laboratory findings and insemination results with the Hülsenberger Pailleten technique. Deut Tierarztl Woch 82: 261-300. 